\title{
NADH Dehydrogenase Deficiency
}

National Cancer Institute

\section{Source}

National Cancer Institute. NADH Dehydrogenase Deficiency. NCI Thesaurus. Code C98994.

A rare metabolic disorder characterized by the deficiency of mitochondrial NADH dehydrogenase component of complex I. Signs and symptoms include cardiomyopathy, encephalopathy, enlarged head, and progressive leukodystrophy. 